\title{
Precipitation Behavior and Microstructural Evolution of Ferritic Ti-V- Mo Complex Microalloyed Steel
}

\author{
Ke Zhang ${ }^{1,2} \cdot$ Hui Wang ${ }^{1,2} \cdot$ Xin-Jun Sun ${ }^{3} \cdot$ Feng-Li Sui ${ }^{1,2} \cdot$ Zhao-Dong Li $^{3} \cdot$ En-Xiang Pu ${ }^{3} \cdot$ Zheng-Hai Zhu $^{1,2} \cdot$ \\ Zhen-Yi Huang ${ }^{1,2} \cdot$ Hong-Bo Pan ${ }^{1,2} \cdot$ Qi-Long Yong ${ }^{3}$
}

Received: 10 December 2017 / Revised: 6 February 2018/Published online: 9 April 2018

(C) The Chinese Society for Metals and Springer-Verlag GmbH Germany, part of Springer Nature 2018

\begin{abstract}
Precipitation behavior of ( $\mathrm{Ti}, \mathrm{V}, \mathrm{Mo}) \mathrm{C}$ and microstructural evolution of the ferritic Ti-V-Mo complex microalloyed steel were investigated through changing coiling temperature (CT). It is demonstrated that the strength of the Ti-V-Mo microalloyed steel can be ascribed to the combination of grain refinement hardening and precipitation hardening. The variation of hardness (from 318 to $415 \mathrm{HV}$, then to $327 \mathrm{HV}$ ) with CT (from 500 to $600-625{ }^{\circ} \mathrm{C}$, then to $700{ }^{\circ} \mathrm{C}$ ) was attributed to the changes of volume fraction and particle size of (Ti, V, Mo)C precipitates. The optimum CT was considered as $600-625^{\circ} \mathrm{C}$, at which the maximum hardness value $(415 \mathrm{HV})$ can be obtained. It was found that the atomic ratios of $\mathrm{Ti}, \mathrm{V}$ and $\mathrm{Mo}$ in $(\mathrm{Ti}, \mathrm{V}, \mathrm{Mo}) \mathrm{C}$ carbides were changed as the $\mathrm{CT}$ increased. The precipitates with the size of $<10 \mathrm{~nm}$ were the $\mathrm{V}$-rich particles at higher $\mathrm{CT}$ of 600 and $650{ }^{\circ} \mathrm{C}$, while the Ti-rich particles were observed at lower $\mathrm{CT}$ of 500 and $550^{\circ} \mathrm{C}$. Theoretical calculations indicated that the maximum nucleation rate of (Ti, V, Mo)C in ferrite matrix occurred around $630{ }^{\circ} \mathrm{C}$, which was consistent with the $625^{\circ} \mathrm{C}$ obtained from experiment results.
\end{abstract}

Keywords Nano-sized precipitates $\cdot$ Precipitation hardening $\cdot$ Ti-V-Mo $\cdot$ Coiling temperature $\cdot$ Ferrite

\section{Introduction}

Hot rolled high strength sheet steels are now widely used as the structural steels in buildings, vessels, facilities, line pipes, heavy construction equipments, etc. With the unprecedented environmental challenges to mankind nowadays, such as global warming and smog, it is critical to develop and use the ultra-high strength steels ( $>1000 \mathrm{MPa}$ tensile strength) to dramatically reduce the

Available online at http://link.springer.com/journal/40195.

Ke Zhang

huzhude@yeah.net

Zheng-Hai Zhu

zhu_zhenghai@163.com

$1 \quad$ Key Laboratory of Metallurgical Emission Reduction and Resources Recycling, Anhui University of Technology, Ministry of Education, Maanshan 243032, China

2 School of Metallurgical Engineering, Anhui University of Technology, Maanshan 243032, China

3 Central Iron and Steel Research Institute, Beijing 100081, China amount of common low strength steels now in use. Nanoscale co-precipitation strengthening in steels has received increasing attention in recent years and has become a new cornerstone for developing advanced steels with superior combination of high strength, high toughness and excellent weldability for a new era [1]. Recently, the Ti-Mo [2, 3], $\mathrm{Ti}-\mathrm{V}$ [4-7], Ti-Nb [8], Ti-V-Nb [9-12], Ti-Nb-Mo [13, 14], Ti-V-Mo [15, 16] complex microalloyed steels with precipitation hardening were systematically developed and studied by a combination of careful thermo-mechanical controlled processing (TMCP). As is well known, an addition of Ti element can make a great contribution to increase the strength of microalloyed steels through precipitation hardening without seriously deteriorating their ductilities. Moreover, Ti has great advantages of low cost and abundant resources. Thus, it is necessary and practically significant to investigate the Ti-contained complex microalloyed steel with excellent mechanical properties [17].

In the hot rolled steel strip, the microstructure and mechanical properties are greatly affected by the process parameters, such as the rolling ratio, rolling temperature, cooling rate, and coiling temperature (CT). Among them, 
the influence of CT is considered to be the most significant [18, 19], particularly in controlling the precipitation strengthening of microalloyed elements. There is no doubt that controlling $\mathrm{CT}$ is the most economical and efficient way to improve the properties of microalloyed steels. Moreover, the CT is associated with the precipitation of microalloying elements, such as $\mathrm{Ti}, \mathrm{Nb}, \mathrm{V}$ and Mo [20], which is expected to play a strengthening role via nanoscale carbides. Recently, a new hot rolled complex microalloyed low carbon steel with a yield strength of $1080 \mathrm{MPa}$ and a elongation of $13.2 \%$ by adding Ti, V and Mo and controlling the CT was developed [16]. The results revealed that the $\mathrm{CT}$ played a critical role in refining the precipitate size and improving the volume fraction of $(\mathrm{Ti}$, $\mathrm{V}$, Mo)C carbides, and these precipitates provided a large increment of precipitation hardening about 444-487 MPa. However, the precipitation behavior, microstructure characteristics and precipitation kinetics of complex ( $\mathrm{Ti}, \mathrm{V}$, $\mathrm{Mo}) \mathrm{C}$ carbides in ferrite have not been investigated. Furthermore, to the authors' knowledge, there is still less attention paid to this subject. For maximizing the increment of precipitation hardening in ferrite, a careful examination to understand the precipitation behavior, microstructural evolution as a function of CT in ferrite is essentially required for developing hot rolled ultra-high strength ( $>1000 \mathrm{MPa}$ tensile strength) steels.

In this work, the influence of $\mathrm{CT}$ on microstructural evolution, precipitation and hardness of Ti-V-Mo microalloyed steel is explained in detail. Furthermore, the precipitation behavior and characteristics of complex (Ti, $\mathrm{V}, \mathrm{Mo}) \mathrm{C}$ carbides are discussed.

\section{Experimental}

In this work, a steel with composition (wt\%) of $0.16 \mathrm{C}$, $0.16 \mathrm{Si}, 1.04 \mathrm{Mn}, 1.0(\mathrm{Ti}+\mathrm{V}+\mathrm{Mo}), 0.0052 \mathrm{~S}, 0.0041 \mathrm{P}$, $0.0046 \mathrm{~N}, 0.033 \mathrm{Al}, \mathrm{Fe}$ (balance) was chosen. Figure 1 shows the schematic illustration of TMCP schedule. The precipitation dissolution temperature $\left(1327^{\circ} \mathrm{C}\right)$ and

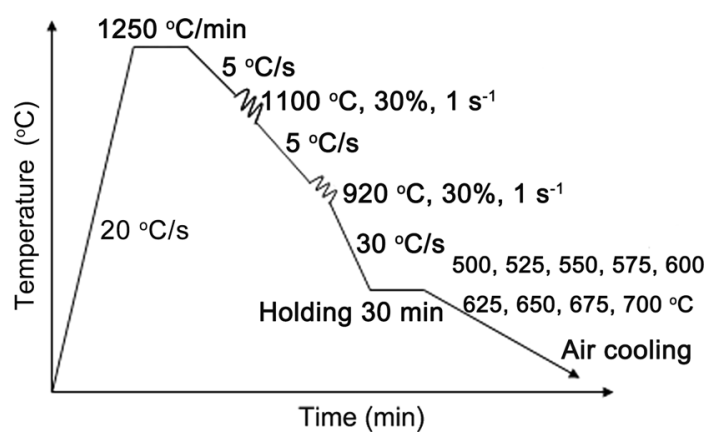

Fig. 1 Schematic illustration describing TMCP schedule equilibrium temperatures $\left(A_{\mathrm{e} 3}=878^{\circ} \mathrm{C}\right.$ and $A_{\mathrm{e} 1}=758^{\circ} \mathrm{C}$; $A_{\mathrm{e} 3}$ represents the highest transformation temperature of austenite and ferrite in the equilibrium state; $A_{\mathrm{e} 1}$ refers to the transformation temperature between austenite and pearlite in the equilibrium state) were calculated using the Thermo-Calc software with the TCFE3 database (CISRITCS Joint Open Laboratory). Uniaxial compression samples with a height of $15 \mathrm{~mm}$ and a diameter of $10 \mathrm{~mm}$ were heated to $1250{ }^{\circ} \mathrm{C}$ at a rate of $20{ }^{\circ} \mathrm{C} / \mathrm{s}$ and held for $3 \mathrm{~min}$. Next, samples were cooled at a rate of $5{ }^{\circ} \mathrm{C} / \mathrm{s}$ to $1100{ }^{\circ} \mathrm{C}$ followed by a deformation strain of $30 \%$ at a strain rate of $1 \mathrm{~s}^{-1}$, then, further cooled to $920{ }^{\circ} \mathrm{C}$ at a rate of $5{ }^{\circ} \mathrm{C} / \mathrm{s}$ and deformed continuously to a strain of $30 \%$ at the same strain rate. To avoid austenite decomposition during cooling, the samples were cooled at $30{ }^{\circ} \mathrm{C} / \mathrm{s}$ to each isothermal holding temperature of $500,525,550,575,600,625,650,675$ and $700{ }^{\circ} \mathrm{C}$ and held at that temperature for $30 \mathrm{~min}$ followed by air cooling to room temperature. The samples prepared at various CTs were designated as 500, 550, 600 and $650{ }^{\circ} \mathrm{C}$ by reflecting the $\mathrm{CT}$.

The samples for the optical microscopy (OM) and scanning electron microscope (SEM) analysis were prepared in an etchant of $4 \%$ nital after the standard mechanical polishing. Electron backscattered diffraction (EBSD) was used to identify the size of ferrite grain, in which a step size of $0.2 \mu \mathrm{m}$ was used. The samples for EBSD examination were first ground by the conventional grinding papers and then electro-polished using $92 \%$ acetic acid and $8 \%$ perchloric acid at $60 \mathrm{~V}$ at room temperature for $10 \mathrm{~s}$. The acquired EBSD data was interpreted by the orientation imaging microscope analysis software. The thin foils for high resolution transmission electron microscopy (HRTEM) were prepared by twin-jet electrolytic polishing in an electrolyte of $6 \%$ perchloric acid. The carbon extraction replica technique was used for the observation of the precipitates by HRTEM. In addition, the energy dispersive X-ray spectroscopy (EDS) was used to identify the composition of the precipitates during the HRTEM analysis. The hardness was determined with VH5 Vickers hardness tester at a $5 \mathrm{~kg}$ load.

According to the theories of classical nucleation and Ostwald ripening [21], the precipitation-time-temperature (PTT) curve, nucleation-temperature (NrT) curve and coarsening rate of carbides in ferrite were calculated by choosing relevant kinetic parameters in ferrite [22], which will be given in Sects. 4.2 and 4.3 in detail. It is assumed that the amount of deformation induced precipitates of austenite occured about $50 \%$ after the final rolling of $920{ }^{\circ} \mathrm{C}$. 


\section{Results}

\subsection{Microstructure}

Optical observation was carried out for samples coiled at different CTs, as shown in Fig. 2. It revealed that single acicular ferrite was obtained at $500{ }^{\circ} \mathrm{C}$ (Fig. 2a). With increasing CT from 525 to $575{ }^{\circ} \mathrm{C}$, polygonal ferrite and acicular ferrite were formed and the fraction of polygonal ferrite was increased as the CT increases (Fig. 2b-d). Full polygonal grey ferrites were formed at or above $600{ }^{\circ} \mathrm{C}$ (Fig. 2e-i). Unetched ferrite grain boundaries indicated that most of the interstitial carbon atoms were consumed due to the formation of carbides.

To reveal the microstructural evolution clearly, the fine microstructure was analyzed by SEM, as shown in Fig. 3. An acicular ferrite microstructure was observed in sample at $500{ }^{\circ} \mathrm{C}$, and the microstructure consisted of acicular ferrite with small amounts of polygonal ferrite at $550{ }^{\circ} \mathrm{C}$ (Fig. 3b). Nevertheless, when the CT is as high as 600 and $650{ }^{\circ} \mathrm{C}$, a fully polygonal ferrite was observed (Fig. 3c, d).

EBSD images showing the grain structure of samples at different CTs are presented in Fig. 4, where the ferrite grain boundaries $\left(\theta \geq 15^{\circ}, \theta\right.$ represents misorientation of grain boundaries) and low angle grain boundaries (LAB) $\left(2^{\circ} \leq \theta<15^{\circ}\right)$ composed of dislocations, are indicated as black and blue lines, respectively. The microstructures of sample at CTs of 500 and $550{ }^{\circ} \mathrm{C}$ were composed of acicular and polygonal shaped ferrite. However, full polygonal ferrite was obtained at CTs of 600,650 and $700{ }^{\circ} \mathrm{C}$. It is worthwhile to note that the fractions of $\mathrm{LAB}$ of 650 and $700{ }^{\circ} \mathrm{C}$ were much lower than those of 500 and $550{ }^{\circ} \mathrm{C}$. According to the linear intercept method, the average grain sizes were measured to be $2.52,2.52,2.66,3.46$ and $4.02 \mu \mathrm{m}$ for samples at 500, 550, 600, 650 and $700{ }^{\circ} \mathrm{C}$, respectively. It can be seen that the most homogenous distribution of ferrite grain was obtained at the CT of $600{ }^{\circ} \mathrm{C}$. With the $\mathrm{CT}$ increasing from 550 to $700{ }^{\circ} \mathrm{C}$, the average grain size of various samples increases slightly, but the uniformity becomes poor.

\subsection{Phases}

TEM images and size distribution of particles $(\leq 20 \mathrm{~nm})$ of the steels coiled at 500, 550,600, 650 and $700{ }^{\circ} \mathrm{C}$ are presented in Fig. 5. It was seen that the amount of precipitates increased and the average size of carbides coarsened when the CT was raised. At the $\mathrm{CT}$ of $500{ }^{\circ} \mathrm{C}$, the
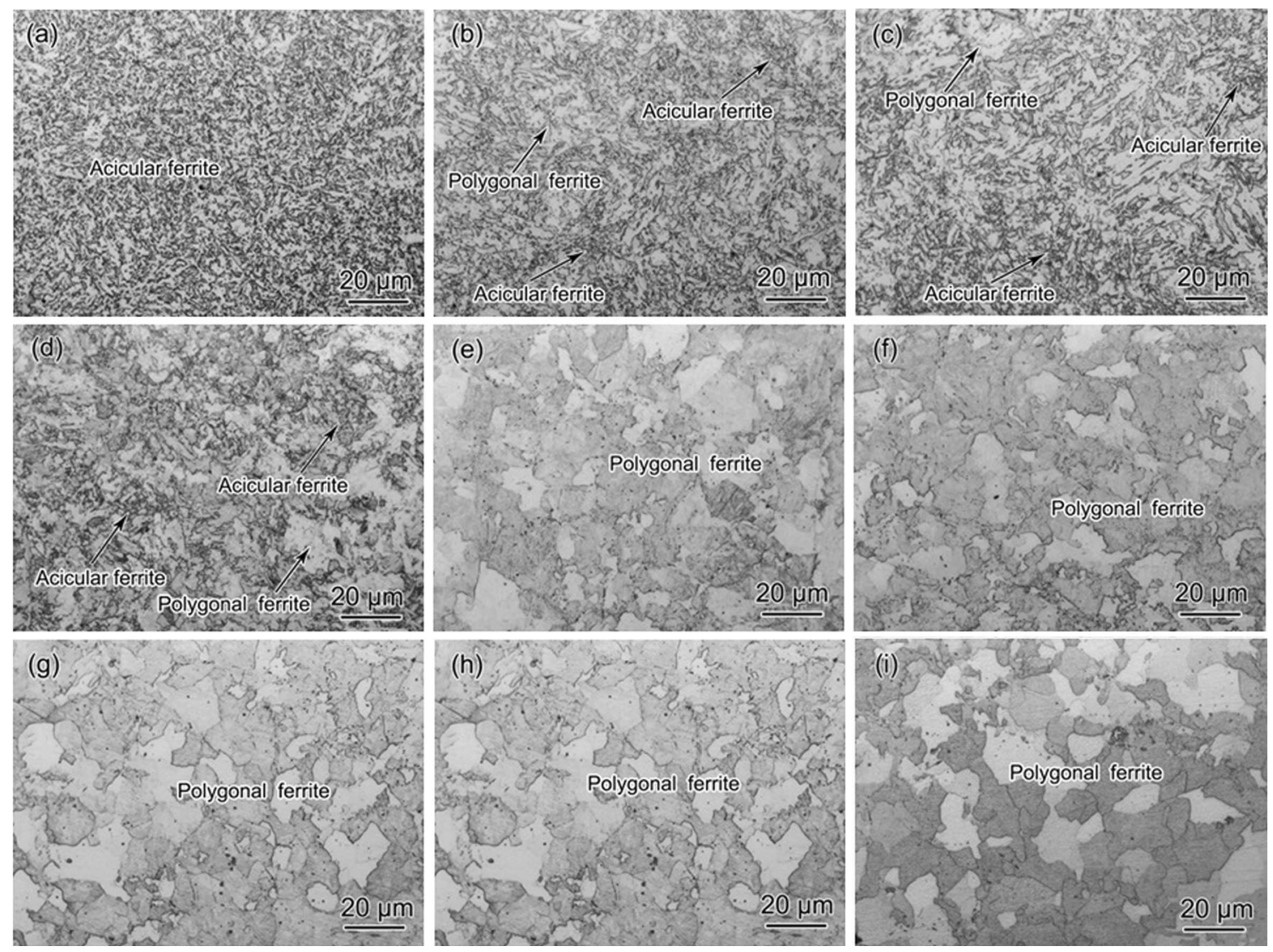

Fig. $2 \mathrm{OM}$ images of Ti-V-Mo steels at $\mathrm{CTs}$ of $500{ }^{\circ} \mathrm{C} \mathrm{a}, 525{ }^{\circ} \mathrm{C} \mathrm{b}, 550{ }^{\circ} \mathrm{C} \mathbf{c}, 575{ }^{\circ} \mathrm{C} \mathrm{d}, 600{ }^{\circ} \mathrm{C} \mathbf{e}, 625{ }^{\circ} \mathrm{C} \mathbf{f}, 650{ }^{\circ} \mathrm{C} \mathrm{g}, 675{ }^{\circ} \mathrm{C} \mathbf{h}, 700{ }^{\circ} \mathrm{C} \mathbf{i}$ 

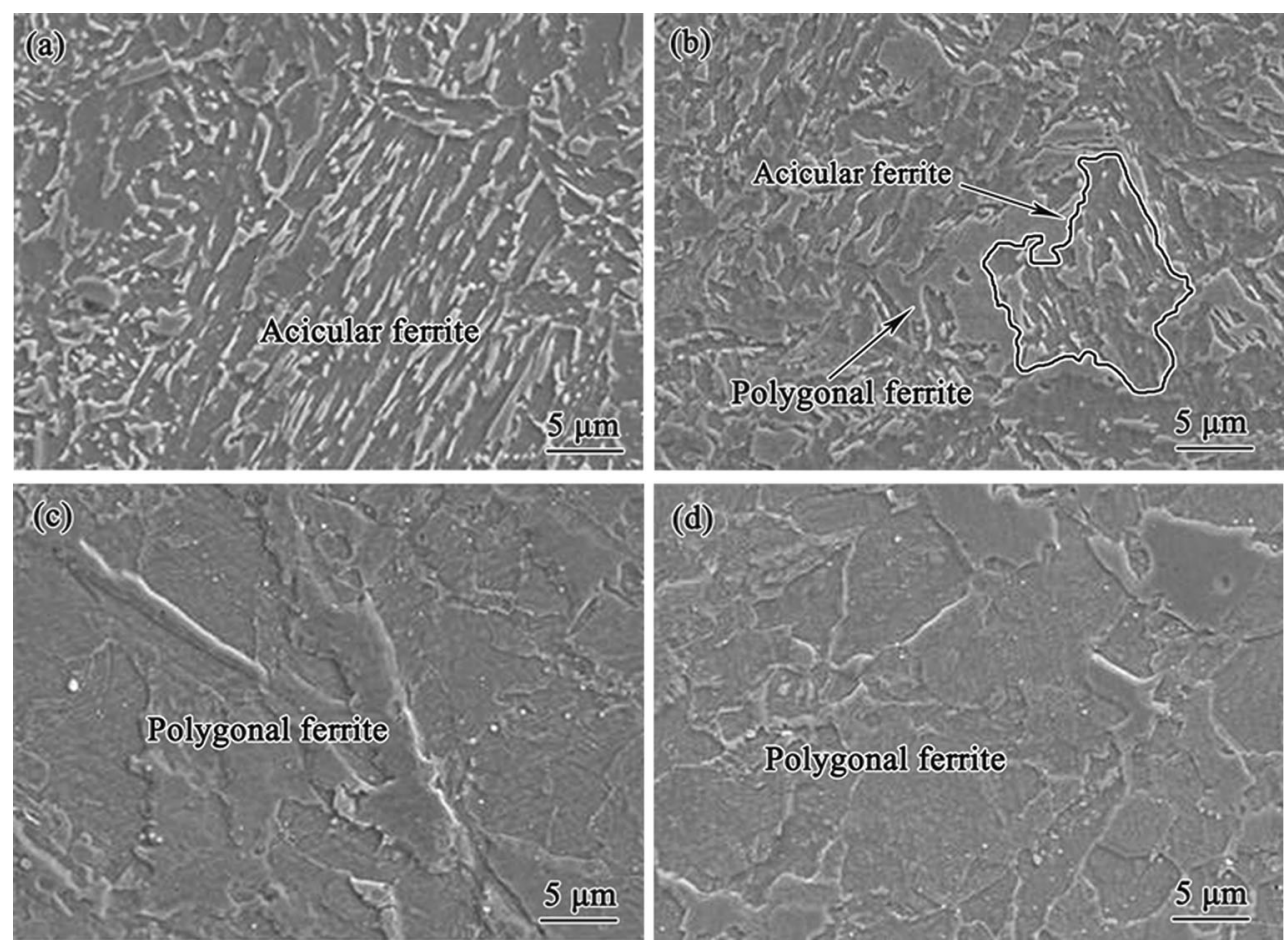

Fig. 3 SEM images of Ti-V-Mo steels at CTs of $500{ }^{\circ} \mathrm{C}$ a, $550{ }^{\circ} \mathrm{C} \mathrm{b}, 600{ }^{\circ} \mathrm{C} \mathbf{c}, 650{ }^{\circ} \mathrm{C} \mathrm{d}$
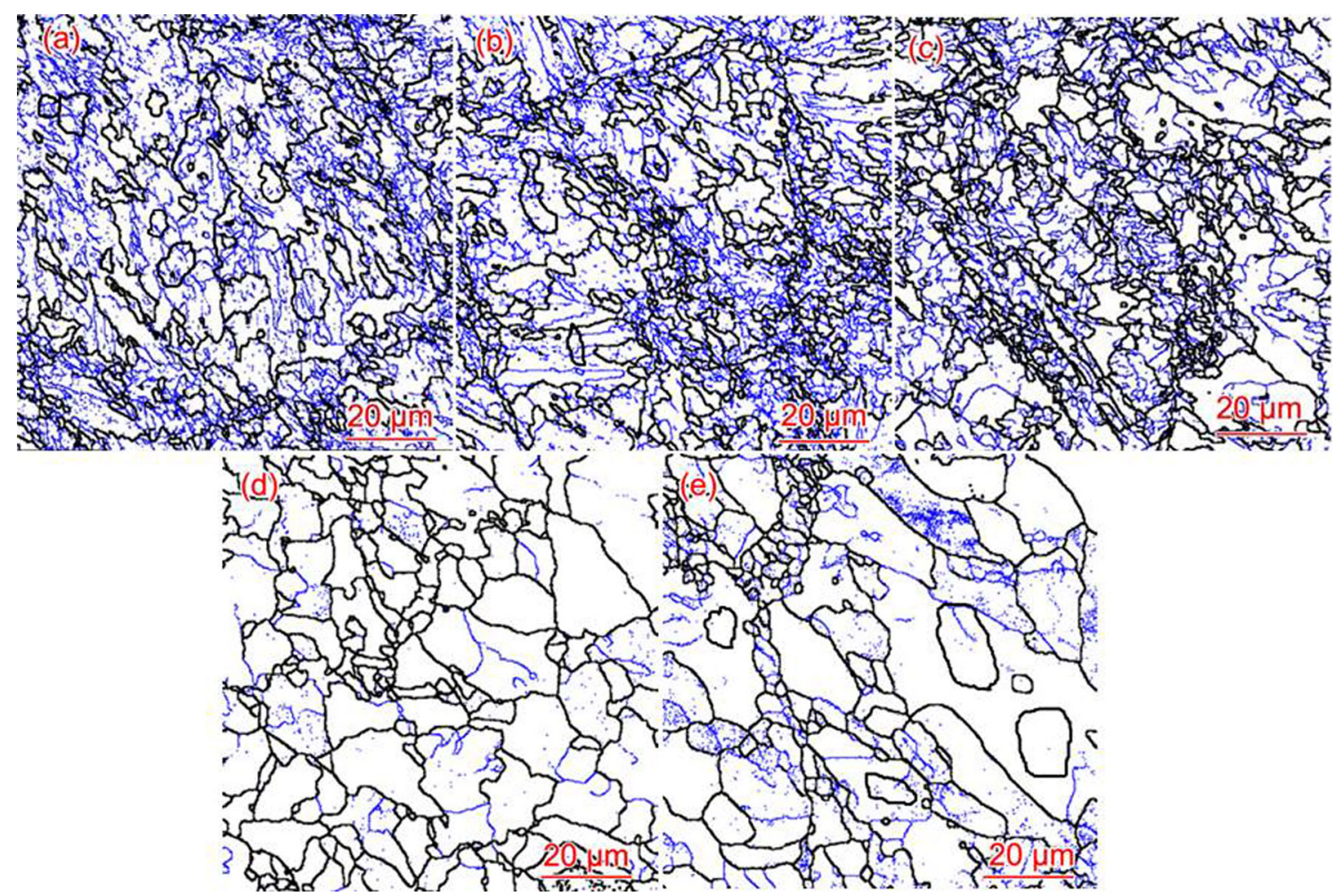

Fig. 4 EBSD images of Ti-V-Mo steels at CTs of $500{ }^{\circ} \mathrm{C} \mathrm{a}, 550{ }^{\circ} \mathrm{C} \mathrm{b}, 600{ }^{\circ} \mathrm{C} \mathrm{c}, 650{ }^{\circ} \mathrm{C} \mathrm{d}, 700{ }^{\circ} \mathrm{C}$ e

precipitates were scarce and their distribution was clearly not uniform (Fig. 5a). As the CT increases to 550 and $600{ }^{\circ} \mathrm{C}$, the amount of precipitates increased, and they were uniformly distributed in the matrix with the size less than $10 \mathrm{~nm}$ (Fig. 5b, c). Moreover, the particle size of sample $650{ }^{\circ} \mathrm{C}$ was larger than that of sample $600{ }^{\circ} \mathrm{C}$, and 

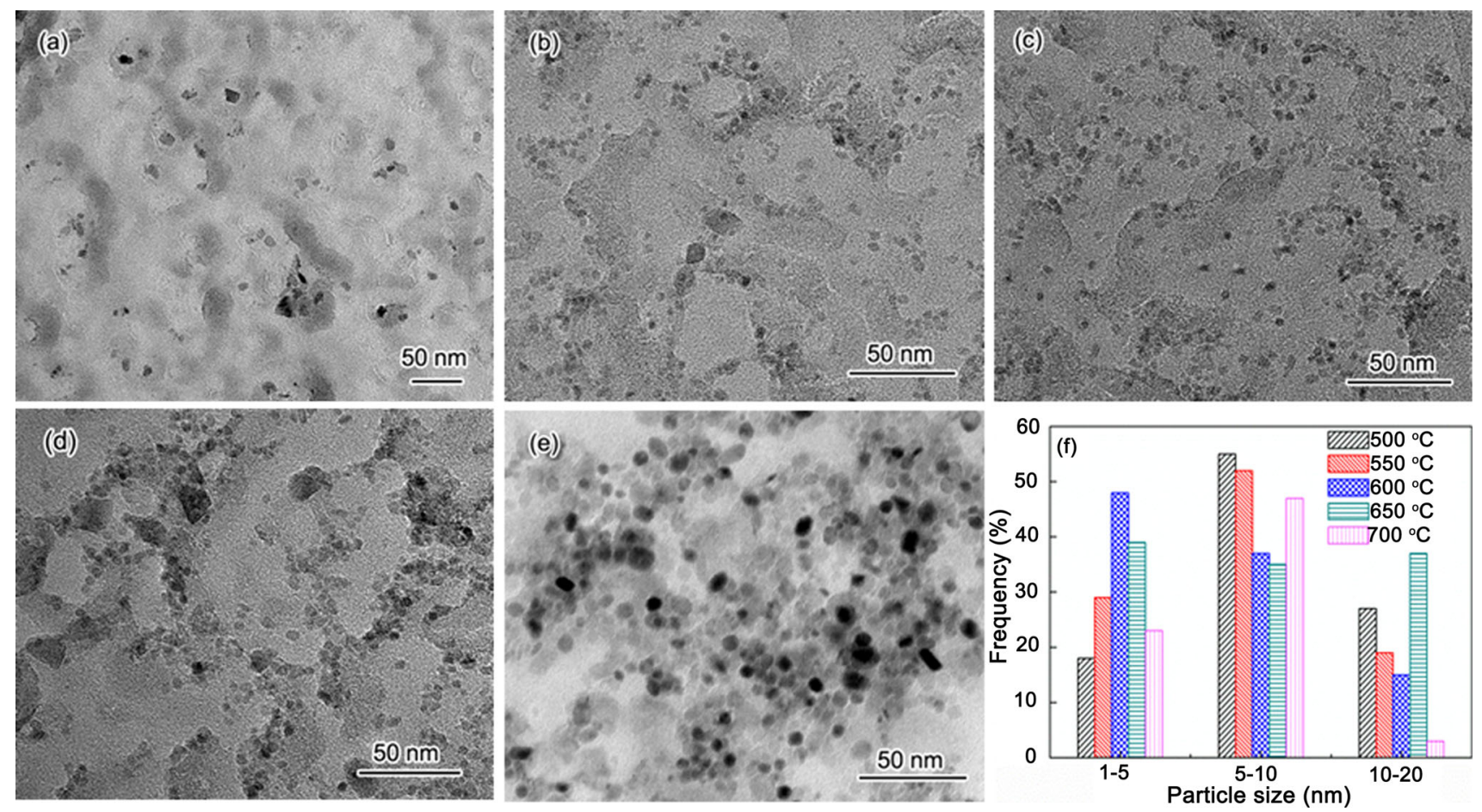

Fig. 5 TEM images of nano-scale particle precipitation at CTs of $500{ }^{\circ} \mathrm{C} \mathrm{a}, 550{ }^{\circ} \mathrm{C} \mathrm{b}, 600{ }^{\circ} \mathrm{C} \mathrm{c}, 650{ }^{\circ} \mathrm{C} \mathrm{d}, 700{ }^{\circ} \mathrm{C} \mathbf{e}$, particle size distribution of different CTs $\mathbf{f}$

the proportion of large particles $(>10 \mathrm{~nm})$ increased obviously (Fig. 5d, e). It was obvious that the mean size of precipitates of sample $700{ }^{\circ} \mathrm{C}$ was the largest among all samples. As shown in Fig. 5f, the proportion of particles $(<5 \mathrm{~nm})$ has also increased as the CT increased from 500 to $600{ }^{\circ} \mathrm{C}$. However, when the $\mathrm{CT}$ continuously raised to 650 and $700{ }^{\circ} \mathrm{C}$, the proportion of precipitates $(<5 \mathrm{~nm})$ decreased and the particles with the size of $5-10 \mathrm{~nm}$ increased remarkably (Fig. 5f).

The EDS analysis of precipitates with the size $<20 \mathrm{~nm}$ of different CTs was used to identify their compositions by measuring 20 particles. The results showed that these particles are (Ti, V, Mo)C with different contents of $\mathrm{Ti}, \mathrm{V}$ and Mo, and the mean atom ratios of $\mathrm{Ti}, \mathrm{V}$ and $\mathrm{Mo}$ in (Ti, $\mathrm{V}, \mathrm{Mo}) \mathrm{C}$ particles of each $\mathrm{CT}$ are shown in Fig. 6. At the lower CTs of 500 and $550{ }^{\circ} \mathrm{C}$, the atom ratio of $\mathrm{Ti}$ in (Ti, $\mathrm{V}, \mathrm{Mo}) \mathrm{C}$ precipitates was dominated and higher than $50 \%$, while the atom ratio of $\mathrm{V}$ was only around $20 \%$, which indicated these carbides were rich in Ti. Nevertheless, the atom ratio of $\mathrm{V}$ in $(\mathrm{Ti}, \mathrm{V}, \mathrm{Mo}) \mathrm{C}$ precipitates was dominated and higher than $60 \%$ at the CTs of 600 and $650{ }^{\circ} \mathrm{C}$, while the atom ratio of $\mathrm{Ti}$ was about $10 \%$, and the carbides were rich in $\mathrm{V}$.

HRTEM images of a nano-scale precipitate in ferrite matrix are presented in Fig. 7. From these images, the morphology and crystal structure were obtained, and the corresponding electron diffraction pattern was identified by the fast Fourier transformation (FFT) diffractogram.

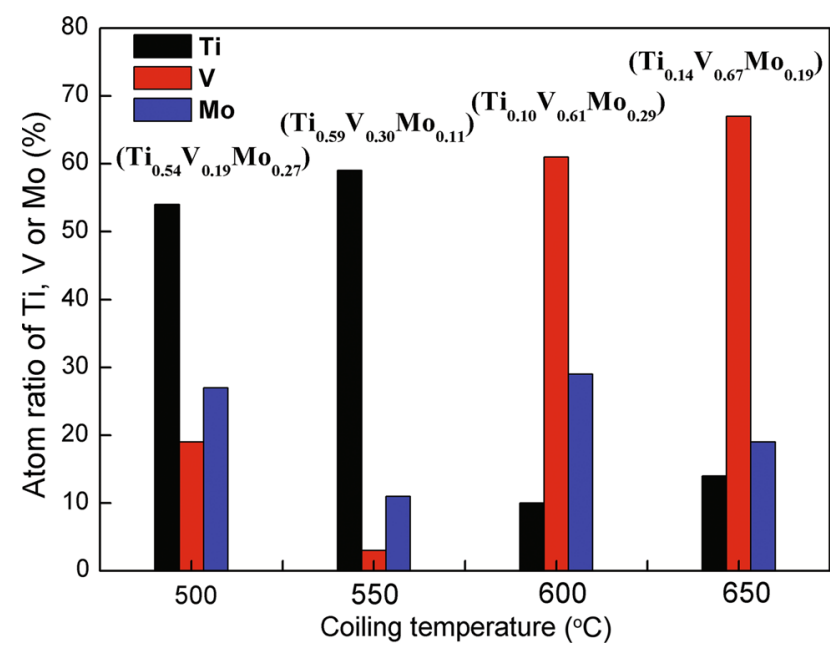

Fig. 6 Atom ratios of $\mathrm{Ti}, \mathrm{V}$ or $\mathrm{Mo}$ in $(\mathrm{Ti}, \mathrm{V}, \mathrm{Mo}) \mathrm{C}$ particles at different CTs

Moreover, it was further confirmed that the (Ti, V, Mo)C particle was face-centered cubic structure with a length of $\sim 6.6 \mathrm{~nm}$ and a thickness of $\sim 4.9 \mathrm{~nm}$ (Fig. 7a, d). The orientation relationship (OR) with respect to the ferrite matrix was shown as followed: $(011)_{\alpha-\mathrm{Fe}} \|(200)_{\mathrm{TiC}}$ and $[011]_{\alpha-\mathrm{Fe}} \|[011]_{\mathrm{TiC}}$ (Fig. 7). This was probably a variant resulted from the Baker-Nutting (BN) OR [23], because the zone axis [011] was chosen for HRTEM observation. That means the fine $(\mathrm{Ti}, \mathrm{V}, \mathrm{Mo}) \mathrm{C}(1-10 \mathrm{~nm})$ precipitated 

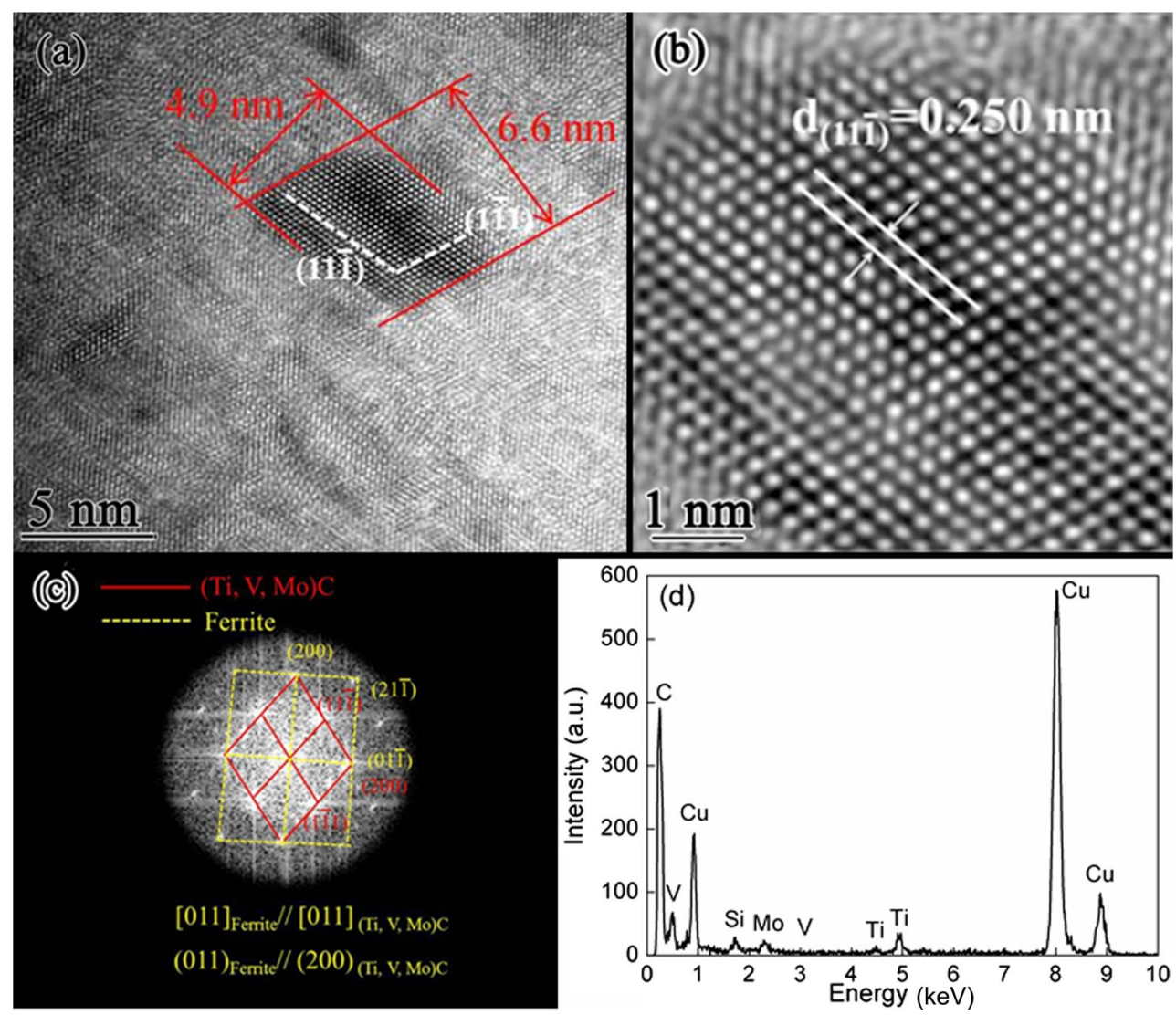

Fig. 7 HRTEM image of a particle of ferrite matrix at CT of $600{ }^{\circ} \mathrm{C} \mathbf{a}$, magnified HRTEM image of $\mathbf{a}$, $\mathbf{b}$, corresponding fast Fourier transformed diffractogram $\mathbf{c}$, EDS analysis of particle in $\mathbf{a}, \mathbf{d}$

coherently in ferrite during isothermally holding. It is clearly verified from the EDS that the particle is (Ti, V, Mo)C (Fig. 7d).

\subsection{Hardness}

The hardness values as a function of CTs are plotted in Fig. 8. The hardness plot could be divided into three regions: (1) Region I represents the continuous increase of

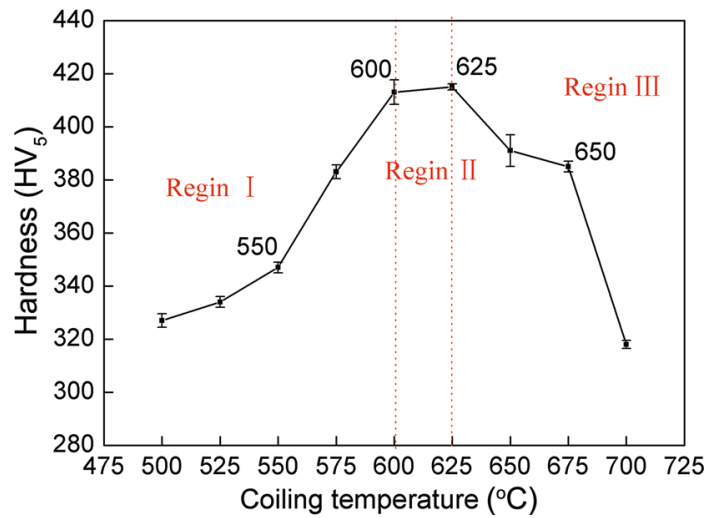

Fig. 8 Variations of hardness as a function of different CTs hardness at CTs from 500 to $600{ }^{\circ} \mathrm{C}$, the corresponding hardness is increased from 327 to $415 \mathrm{HV}$; (2) Region II corresponds to the region from 600 to $625{ }^{\circ} \mathrm{C}$, where the highest hardness was almost constant (about $415 \mathrm{HV}$ ); (3) Region III shows a fast reduction in hardness over $625^{\circ} \mathrm{C}$, and the value of hardness decreased rapidly from $415 \mathrm{HV}$ at $625^{\circ} \mathrm{C}$ to $318 \mathrm{HV}$ at $700{ }^{\circ} \mathrm{C}$ (Fig. 8).

\section{Discussion}

\subsection{Effect of CT on Microstructural Evolution}

The samples at CT from 500 to $700{ }^{\circ} \mathrm{C}$ were selected for microstructure characterization using OM and SEM. With the CT increasing from 500 to $700{ }^{\circ} \mathrm{C}$, the microstructure was changed from acicular ferrite at $500{ }^{\circ} \mathrm{C}$ to acicular ferrite and polygonal ferrite during $525-575{ }^{\circ} \mathrm{C}$, and then to polygonal ferrite dominated in the range of $600-700{ }^{\circ} \mathrm{C}$. A large number of austenites could not decompose and transform completely until coiled at the holding CTs because of a fast cooling rate $\left(30^{\circ} \mathrm{C} / \mathrm{s}\right)$. Due to the lower $\mathrm{CT}$ of $500{ }^{\circ} \mathrm{C}$, the slow self-diffusion of $\mathrm{Fe}$ atom made the ferrite difficult to grow up. Thus, the shape of ferrite was 
changed to disc or need-like due to the increase in coherent interfaces, and then granular bainite was expected to be formed [24]. However, since the diffusion rates of $\mathrm{Fe}$ and $\mathrm{C}$ atoms were enhanced as the CT increases to 525, 550 and $575^{\circ} \mathrm{C}$, the microstructure of these samples was mostly acicular ferrite and polygonal ferrite (Fig. 1b-d). When the CT was kept in a low temperature region from 525 to $575{ }^{\circ} \mathrm{C}$, the higher the temperature, the more proportion of ferrite occupied in the microstructure. As pointed out by Zhao et al. [25], acicular ferrite is an independent type of microstructure in the middle temperature transformation, and the phase transition temperature range is between 530 and $550{ }^{\circ} \mathrm{C}$, which is consistent with the results of this work. The diffusivity of alloy elements was remarkably enhanced during isothermally holding at $600{ }^{\circ} \mathrm{C}$ or even higher temperature [7], and the austenite to ferrite transformation can be completed during the coiling process, and so polygonal ferrite was obtained in the range of 600-700 ${ }^{\circ} \mathrm{C}$ (Figs. 2e-i, 4c-e).

\subsection{Effect of CT on Precipitation Behavior of (Ti, $\mathrm{V}, \mathrm{Mo}) \mathrm{C}$}

For the tested steels at different CTs in the range of 500-700 ${ }^{\circ} \mathrm{C}$, the austenite to ferrite transformation would occur especially at $600-700{ }^{\circ} \mathrm{C}$. Although the phenomenon known as interphase precipitation could happen theoretically $[9,13]$, it is not observed in Fig. 5. This may be that the interphase precipitated carbides can be only observed clearly when the plane of carbides precipitated is approximately perpendicular to the observation plane [26].

As presented in Fig. 9a, the fastest precipitation temperature of $(\mathrm{Ti}, \mathrm{V}, \mathrm{Mo}) \mathrm{C}$ was observed to be approached around $720{ }^{\circ} \mathrm{C}$. The lower the temperature below $700{ }^{\circ} \mathrm{C}$, the longer the fastest precipitation time of carbides. In other words, (Ti, V, Mo)C carbides were more easily precipitated from ferrite matrix because of the kinetic diffusibility of $\mathrm{Ti}, \mathrm{V}$, and Mo remarkable enhanced as the CT increases from 500 to $700{ }^{\circ} \mathrm{C}$, which corresponded to the amount of $(\mathrm{Ti}, \mathrm{V}, \mathrm{Mo}) \mathrm{C}$ increased as the $\mathrm{CT}$ increases from 500 to $600{ }^{\circ} \mathrm{C}$ (Fig. 5c), despite the equilibrium solubility of carbides decreased slightly. However, the NrT curve of $(\mathrm{Ti}, \mathrm{V}, \mathrm{Mo}) \mathrm{C}$ in ferrite showed a "C" shape (Fig. 9b), and the largest nucleation temperature of ( $\mathrm{Ti}, \mathrm{V}$, $\mathrm{Mo}) \mathrm{C}$ in ferrite was about $630{ }^{\circ} \mathrm{C}$. It can be observed from Fig. $9 \mathrm{~b}$ that the number of precipitates has increased with the temperature increasing from 500 to $630{ }^{\circ} \mathrm{C}$, which is consistent with the trend of the density change of precipitates as a function of CTs (Fig. 5a-c). As the CT reached to $625^{\circ} \mathrm{C}$ or higher, the precipitates with larger size (20-40 nm) were observed (Fig. 5 d, e) because of the higher temperature and the decreasing nucleation rate, which may explain why the hardness of corresponding specimen dropped dramatically without a rapid incremental period, as shown in Fig. 8.

The CT has a significant effect on the composition of the complexed (Ti, V, Mo)C carbides [16]. For the steels at different CTs, the solid solution contents of Ti, V and Mo at different CTs were identical at the final rolling temperature of $920{ }^{\circ} \mathrm{C}$. The results shown in Fig. 6 indicate that these $(\mathrm{Ti}, \mathrm{V}, \mathrm{Mo}) \mathrm{C}$ carbides in the specimens coiled at 500 and $550{ }^{\circ} \mathrm{C}$ are Ti-rich particles, which suggest that only a small amount of $(\mathrm{Ti}, \mathrm{V}, \mathrm{Mo}) \mathrm{C}$ have been precipitated and more stable Ti-rich carbides were preferred. Previous investigation [27] suggested that the finishing time of precipitated carbides decreases rapidly with $\mathrm{CT}$ increasing. In other words, ( $\mathrm{Ti}, \mathrm{V}, \mathrm{Mo}) \mathrm{C}$ particles are not completely precipitated out when the samples are isothermally held for an hour at 500 and $550{ }^{\circ} \mathrm{C}$. When the $\mathrm{CT}$ increases higher than $600{ }^{\circ} \mathrm{C}$, many $(\mathrm{Ti}, \mathrm{V}, \mathrm{Mo}) \mathrm{C}$ particles are easily to be precipitated and they are prone to reach the equilibrium state. Therefore, these $(\mathrm{Ti}, \mathrm{V}, \mathrm{Mo}) \mathrm{C}$ carbides in the
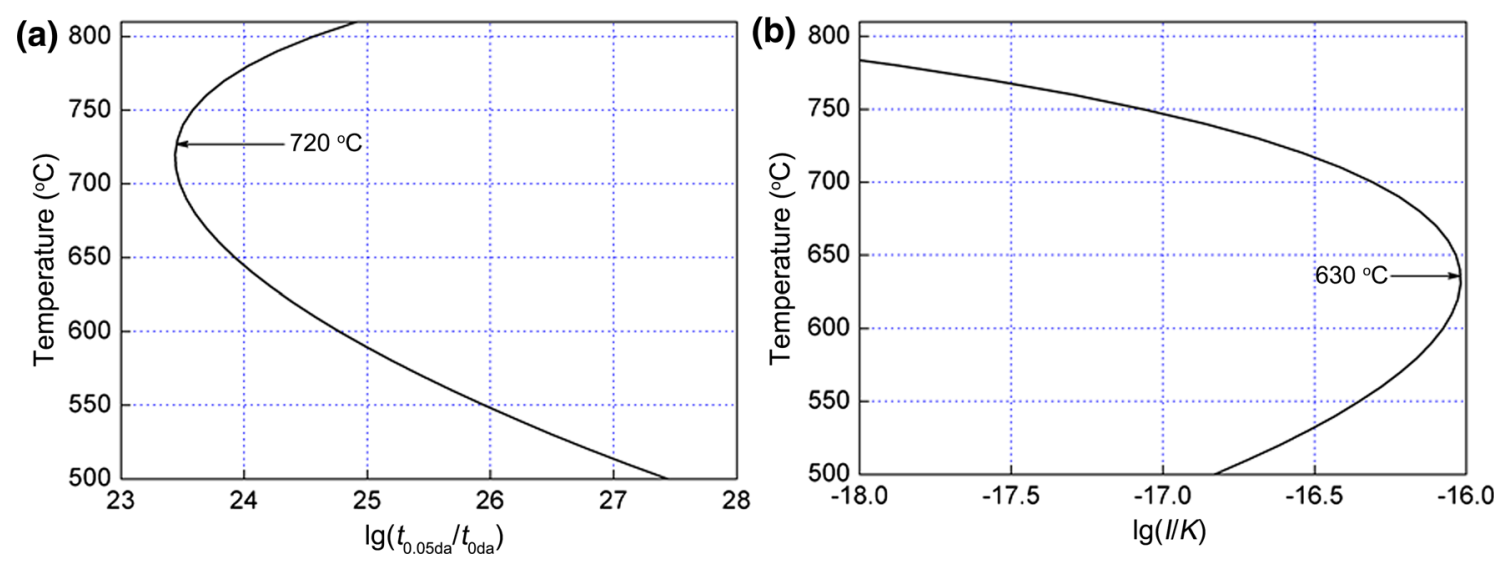

Fig. 9 a PTT, b NrT curves of (Ti, V, Mo)C precipitated from ferrite $\left(t_{0.05 \mathrm{da}}\right.$ : time used to complete volume fraction $5 \%$ of the total (Ti, V, Mo)C precipitated; $t_{0 \mathrm{da}}$ : beginning time of $(\mathrm{Ti}, \mathrm{V}, \mathrm{Mo}) \mathrm{C}$ precipitated; $\lg \left(t_{0.05 \mathrm{da}} / t_{0 \mathrm{da}}\right)$ refers to the relative beginning time of $(\mathrm{Ti}, \mathrm{V}, \mathrm{Mo}) \mathrm{C}$ precipitated; $I$ nucleation rate, $K$ constant independent of temperature) 
samples are V-rich after a small amount of Ti atoms have been precipitated and completely consumed,which is consistent with the $\mathrm{Ti}$ and $\mathrm{V}$ contents of the tested steel (Fig. 6).

\subsection{Effect of CT on Hardness}

With the temperature increasing from 500 to $700{ }^{\circ} \mathrm{C}$, the hardness of samples exhibits a trend of first increasing and then decreasing rapidly (Fig. 8). For a low carbon microalloyed steel, the common strengthening mechanisms includes grain refinement hardening, precipitation hardening, solid solution hardening and dislocation hardening $[6,19]$. Since the microstructure of the investigated steels was mostly ferrite, the solid solution hardening increment and dislocation hardening increment were relatively close for all samples at different CTs [15], respectively. Previous studies $[3,15,16]$ noted that the variations in solid solution hardening increment and dislocation hardening increment at different CTs were minor. Therefore, grain refinement hardening and precipitation hardening are the main factors to influence the strength of ferritic microalloyed steel $[16,19]$. Although the average ferrite grain size slightly increased as CT increases from 500 to $625^{\circ} \mathrm{C}$, the increment is relatively small (Fig. 4). Theoretically, the grain refinement hardening increment reduced slightly and it would result in a slight hardness decrease as the CT increases from 500 to $625^{\circ} \mathrm{C}$. Nevertheless, the hardness actually rises rapidly due to precipitation hardening (Fig. 5a-c). It shows that precipitation hardening played a key role in improving the hardness of the tested steel when the CT increases from 500 to $625^{\circ} \mathrm{C}$.

For the higher temperature from 650 to $700{ }^{\circ} \mathrm{C}$, a marked decrease (about $88 \mathrm{HV}$ ) in hardness is mainly attributed to a rapid coarsening rate of $(\mathrm{Ti}, \mathrm{V}, \mathrm{Mo}) \mathrm{C}$ carbides (Fig. 10) and an increase of ferrite grain size (Fig. 4). Coincidentally, similar studies on Ti-Mo microalloyed steels reported by Chen et al. [18] and Kim et al. [19]

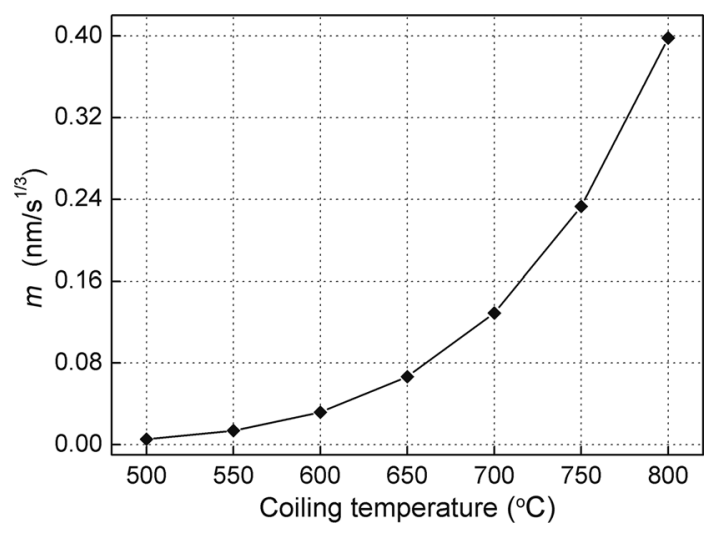

Fig. 10 Coarsening kinetics of $(\mathrm{Ti}, \mathrm{V}, \mathrm{Mo}) \mathrm{C}$ in ferrite pointed out that the samples coiled at about $620^{\circ} \mathrm{C}$ could produce the highest strength and the largest volume fraction of fine precipitates.

Based on the earlier studies [28-30], the finer precipitates nucleated during the coiling process are expected to cause significant strengthening effect on steels, while the larger ones $(>10 \mathrm{~nm})$ are formed in high temperature region and their effect can be weakened to a large extent. If the precipitation behaviors of the steels at different CTs were compared, it was found that the precipitates formed at $600{ }^{\circ} \mathrm{C}$ are relatively finer, and uniformly dispersed in comparison with those precipitates of other CTs (Fig. 5). This difference is attributed to two reasons: first, the relatively smaller diffusion coefficients of $\mathrm{Ti}, \mathrm{V}$ and $\mathrm{Mo}$ restricted precipitation of $(\mathrm{Ti}, \mathrm{V}, \mathrm{Mo}) \mathrm{C}$ as the $\mathrm{CT}$ lower than $600{ }^{\circ} \mathrm{C}$ [15]; second, the coarsening rate of $(\mathrm{Ti}, \mathrm{V}$, Mo)C increased obviously when the $\mathrm{CT}$ are above $600{ }^{\circ} \mathrm{C}$ (Fig. 10). It was demonstrated that the number density of (Ti, V, Mo)C precipitated at $600{ }^{\circ} \mathrm{C}$ is obviously higher than that at other CTs such as 500 and $700{ }^{\circ} \mathrm{C}$, which further confirmed the reasonableness and correctness of theoretical results as shown in Fig. 10. The fast Fourier transform pattern of the image (Fig. 7a, c) taken from the [011] zone axis showed that the steel matrix is still bccstructured and ( $\mathrm{Ti}, \mathrm{V}, \mathrm{Mo}) \mathrm{C}$ precipitates have an ordered fcc structure. A large number of the tiny precipitates have a significant impact on improving the increment of precipitation hardening and strength (Fig. 5c). Additionally, the variation in particle size and number density of $(\mathrm{Ti}, \mathrm{V}$, $\mathrm{Mo}) \mathrm{C}$ of different CTs resulted in the variation of hardness as shown in Fig. 8. That is the reason why the CT of $600{ }^{\circ} \mathrm{C}$ had the largest hardness.

\section{Conclusions}

1. The CT has a significant effect on hardness of the TiV-Mo microalloyed steel. With increasing CT from 500 to $700{ }^{\circ} \mathrm{C}$, the hardness first increased rapidly from 327 to $415 \mathrm{HV}\left(500-600{ }^{\circ} \mathrm{C}\right)$, then remaining stable $415 \mathrm{HV}\left(600-625^{\circ} \mathrm{C}\right)$, and finally decreased quickly to $318 \mathrm{HV}\left(625-700{ }^{\circ} \mathrm{C}\right)$. Optimum $\mathrm{CT}$, whereby the steel achieved the maximum hardness $415 \mathrm{HV}$ at room temperature, is considered as in the range of $600-625{ }^{\circ} \mathrm{C}$, which is consistent with the maximum nucleation rate temperature of the theoretical calculation result.

2. The atomic fractions of $\mathrm{Ti}, \mathrm{V}$ and $\mathrm{Mo}$ in $(\mathrm{Ti}, \mathrm{V}, \mathrm{Mo}) \mathrm{C}$ particles with a size of $\leq 10 \mathrm{~nm}$ were statisticed. It is evident that the precipitates in the samples 600 and $650{ }^{\circ} \mathrm{C}$ mainly contain V-rich $(>60 \%)$ particles, while Ti-rich $(>50 \%)$ particles were found in the samples at 500 and $550{ }^{\circ} \mathrm{C}$. 
3. The increase in hardness from 500 to $600{ }^{\circ} \mathrm{C}$ was attributed to the increase of precipitation hardening increment. However, the decrease in hardness from 625 to $700{ }^{\circ} \mathrm{C}$ could be due to the increase in ferrite grain size and the excessive coarsening of $(\mathrm{Ti}, \mathrm{V}$, Mo)C.

4. (Ti, V, Mo)C particles were nearly spherical with a size of less than $10 \mathrm{~nm}$ precipitated from ferrite matrix, and obeyed the OR with respect to the matrix: $(011)_{\alpha-\mathrm{Fe}}$ $\|(200)_{\mathrm{TiC}}$ and $[011]_{\alpha-\mathrm{Fe}} \|[011]_{\mathrm{TiC}}$. This is probably be a variant of the Baker-Nutting $(\mathrm{BN})$ relationship.

5. The PTT curve of complexed (Ti, V, Mo)C particles in ferrite showed a trend of "C" shape, while the NrT curve showed a trend of inversed " $\mathrm{C}$ " shape, which are consistent with the PTT and NrT curves of simple carbides such as $\mathrm{TiC}$ or $(\mathrm{Ti}, \mathrm{Nb}) \mathrm{C}$.

Acknowledgements This work was supported financially by the National Key Research and Development Program of China (Nos. 2017YFB0305100 and 2017YFB0304700), the National Natural Science Foundation of China (Nos. 51704008 and 51674004), the National Key Basic Research Program of China (No. 2015CB654803), the Science and Technology Foundation of China Iron \& Steel Research Institute Group (No. 15G60530A) and the National Science Foundation of Anhui University of Technology (No. QZ201603). We are grateful to the Central Laboratory of Central Iron and Steel Research Institute, for HRTEM observation.

\section{References}

[1] Z.B. Jiao, J.C. Luan, M.K. Miler, Y.W. Chung, C.T. Liu, Mater. Today 20, 142-154 (2017)

[2] J. Chen, M.Y. Lv, S. Tang, G.D. Wang, Acta Metall. Sin. 50, 524-530 (2014). (in Chinese)

[3] J.Y. Kang, X.J. Sun, Z.D. Li, Q.L. Yong, J. Iron. Steel Res. Int. 27, 50-54 (2015)

[4] Y. Funakawa, T. Shiozaki, K. Tomita, T. Yamamoto, E. Maeda, ISIJ Int. 44, 1945-1951 (2004)

[5] M.P. Phaniraj, Y.M. Shin, J. Lee, N.H. Goo, D.I. Kim, J.Y. Suh, W.S. Jung, J.H. Shim, I.S. Choi, Mater. Sci. Eng. A 633, 1-8 (2015)

[6] K. Zhang, Z.D. Li, Z.Q. Wang, Q.L. Yong, Z.Q. Wang, J. Mater. Res. 31, 1254-1263 (2016)
[7] S. Mukherjee, I. Timokhina, C. Zhu, S.P. Ringer, P.D. Hodgson, J. Alloys Compd. 690, 621-632 (2017)

[8] X.L. Li, Z.D. Wang, Acta Metall. Sin. 51, 417-424 (2015). (in Chinese)

[9] E.J. Chun, H. Do, S. Kim, D.G. Nam, Y.H. Park, N. Kang, Mater. Chem. Phys. 140, 307-315 (2013)

[10] X.L. Li, Z.D. Wang, X.T. Deng, Y.J. Zhang, C.S. Lei, G.D. Wang, Acta Metall. Sin. 51, 784-790 (2015). (in Chinese)

[11] Q.Y. Sha, G.Y. Li, L.F. Qiao, P.Y. Yan, J. Iron. Steel Res. Int. 14, 316-319 (2007). (in Chinese)

[12] H.L. Yi, L.X. Du, G.D. Wang, X.H. Liu, J. Iron. Steel Res. Int. 16, 72-77 (2009)

[13] C.Y. Chen, C.C. Chen, J.R. Yang, Mater. Charact. 88, 69-79 (2014)

[14] F.Z. Bu, X.M. Wang, L. Chen, S.W. Yang, Trans. Mater. Heat Treat. 36, 96-103 (2015). (in Chinese)

[15] K. Zhang, Z.D. Li, X.J. Sun, Q.L. Yong, J.W. Yang, Y.M. Li, P.L. Zhao, Acta Metall. Sin. (Engl. Lett.) 28, 641-648 (2015)

[16] K. Zhang, Q.L. Yong, X.J. Sun, Z.D. Li, P.L. Zhao, Acta Metall. Sin. 5, 529-537 (2016). (in Chinese)

[17] X.P. Mao, Titanium Microalloyed Steel (Metallurgical Industry Press, Beijing, 2016), pp. 21-22. (in Chinese)

[18] C.Y. Chen, C.C. Chen, J.R. Yang, Mater. Sci. Eng. A 626 , 74-79 (2015)

[19] Y.W. Kim, S.W. Song, S.J. Seo, S.G. Hong, C.S. Lee, Mater. Sci. Eng. A 565, 430-438 (2013)

[20] R.D.K. Misra, Z. Jia, R. O’Malley, S.J. Jansto, Mater. Sci. Eng. A 528, 8772-8780 (2011)

[21] Q.L. Yong, Secondary Phases in Steels (Metallurgical Industry Press, Beijing, 2006). (in Chinese)

[22] K. Zhang, Dissertation, Kunming University of Science and Technology, 2016 (in Chinese)

[23] H.W. Yen, C.Y. Chen, T.Y. Wang, C.Y. Huang, J.R. Yang, Mater. Sci. Technol. 26, 421-430 (2013)

[24] J.E. Hilliard, in Phase Transformations, ed. by H.I. Aaronson (ASM, Metals Park, 1970), p. 497

[25] Y.T. Zhao, C.J. Shang, X.I. He, X.L. He, H. Guo, Acta Metall. Sin. 42, 54-58 (2006). (in Chinese)

[26] H.W. Yen, P.Y. Chen, C.Y. Huang, J.R. Yang, Acta Mater. 59, 6264-6274 (2011)

[27] Q.I. Yong, I. Zhen, Acta Metall. Sin. 20, 9-16 (1984). (in Chinese)

[28] Y.H. Yang, J.C. Cao, Y. Gu, Mater. Des. 83, 820-828 (2015)

[29] L. Cheng, Q.W. Cai, B.S. Xie, Z. Ning, X.C. Zhou, G.S. Li, Mater. Sci. Eng. A 651, 185-191 (2016)

[30] I. Timokhina, M.K. Miller, J. Wang, H. Beladi, P. Cizek, P.D. Hodgson, Mater. Des. 111, 222-229 (2016) 